\title{
Self-assembly study of type I collagen extracted from male Wistar Hannover rat tail tendons
}

Jeimmy González-Masís', Jorge M. Cubero-Sesin, Simón Guerrero², Sara González-Camacho³, Yendry Regina Corrales-Ureña ${ }^{4}$, Carlos Redondo-Gómez ${ }^{4}$, José Roberto Vega-Baudrit ${ }^{4,5}$ (D) and Rodolfo J. Gonzalez-Paz ${ }^{4 *}$

\begin{abstract}
Background: Collagen, the most abundant protein in the animal kingdom, represents a promising biomaterial for regenerative medicine applications due to its structural diversity and self-assembling complexity. Despite collagen's widely known structural and functional features, the thermodynamics behind its fibrillogenic self-assembling process is still to be fully understood. In this work we report on a series of spectroscopic, mechanical, morphological and thermodynamic characterizations of high purity type I collagen (with a D-pattern of $65 \mathrm{~nm}$ ) extracted from Wistar Hannover rat tail. Our herein reported results can be of help to elucidate differences in selfassembly states of proteins using ITC to improve the design of energy responsive and dynamic materials for applications in tissue engineering and regenerative medicine.

Methods: Herein we report the systematic study on the self-assembling fibrillogenesis mechanism of type I collagen, we provide morphological and thermodynamic evidence associated to different self-assembly events using ITC titrations. We provide thorough characterization of the effect of $\mathrm{pH}$, effect of salts and protein conformation on self-assembled collagen samples via several complementary biophysical techniques, including circular dichroism (CD), Fourier Transform infrared spectroscopy (FTIR), differential scanning calorimetry (DSC), atomic force microscopy (AFM), scanning electron microscopy (SEM), dynamic mechanical thermal analysis (DMTA) and thermogravimetric analysis (TGA).

Results: Emphasis was made on the use of isothermal titration calorimetry (ITC) for the thermodynamic monitoring of fibrillogenesis stages of the protein. An overall self-assembly enthalpy value of $3.27 \pm 0.85 \mathrm{~J} / \mathrm{mol}$ was found. Different stages of the self-assembly mechanism were identified, initial stages take place at pH values lower than the protein isoelectric point (pl), however, higher energy release events were recorded at collagen's pl. Denatured collagen employed as a control exhibited higher energy absorption at its pl, suggesting different energy exchange mechanisms as a consequence of different aggregation routes.
\end{abstract}

Keywords: Protein aggregation, Fibrillogenic, Isoelectric point, Denatured protein, Regenerative medicine

\footnotetext{
* Correspondence: osarsip@gmail.com

${ }^{4}$ National Nanotechnology Laboratory, National Center for High Technology (LANOTEC-CeNAT-CONARE), 1174-1200, Pavas, San José, Costa Rica

Full list of author information is available at the end of the article
}

C C The Author(s). 2020 Open Access This article is licensed under a Creative Commons Attribution 4.0 International License, which permits use, sharing, adaptation, distribution and reproduction in any medium or format, as long as you give appropriate credit to the original author(s) and the source, provide a link to the Creative Commons licence, and indicate if changes were made. The images or other third party material in this article are included in the article's Creative Commons. licence, unless indicated otherwise in a credit line to the material. If material is not included in the article's Creative Commons licence and your intended use is not permitted by statutory regulation or exceeds the permitted use, you will need to obtain permission directly from the copyright holder. To view a copy of this licence, visit http://creativecommons.org/licenses/by/4.0/ The Creative Commons Public Domain Dedication waiver (http://creativecommons.org/publicdomain/zero/1.0/) applies to the data made available in this article, unless otherwise stated in a credit line to the data. 


\section{Background}

Collagen is one of the most important structural proteins, accounting for up to one quarter of protein biomass in mammals [1]. Collagen is highly abundant in animal extracellular matrixes (ECMs), and carries out not only structural functions, but acts as carrier of biological cues useful to guide cell attachment, patterning and structuring of tissues [2]. Collagen can be used not only as a scaffolding matrix for tissue engineering applications with increasing complexity [3], but also as a coating of non-biological surfaces such as polymers to improve and ensure biocompatibility of the latter [4].

Based on the shape of the fibrils and their morphological arrangements, 25 subtypes of collagen have been identified [5]. Type I, II and III collagen are characterized by their fibrillary nature, whereas type IV collagen is amorphous [6]. Type I collagen is composed of helical domains with 338 repetitions of the short motif (X-YGly; wheTre $\mathrm{X}$ and $\mathrm{Y}$ usually correspond to proline and hydroxyproline) which are displayed at protein $\mathrm{N}$ terminus, whereas the $\mathrm{C}$-terminus presents non-helical domains [5, 7].

Importantly, there is a great demand for type I collagen, since it is the principal proteinaceous constituent of tendons, skin, ligaments and other bone tissues. Rat tail tendons are a suitable collagen source, as the lateral and transverse complex of interchain lysine-derived aldimine crosslinks get easily hydrolized under acidic conditions [8] rendering high purity collagen $[9,10]$. Previously, Xiong et al. characterized and elucidated the collagen sequence from Wistar Hannover Rat tail tendons [2]. However, this previous study did not focus on the morphological and thermodynamically assembly characterization.

Collagen's microstructure is pivotal to a number of biological events, as it helps to determine ECM cues available for cellular signaling [11]. Thus, the ways in which this structure can be modified will become relevant to direct cell response in collagen-based selfassembled materials [12]. The understanding of molecular self-assembly is a crucial factor for the fabrication of nanodevices for bioelectronics, biological actuators, artificial muscles, molecular machines, sensors, and medicine in general [13].

The self-assembly process of collagen has been previously explored [4], for instance, it has been shown that in vitro fibrillogenesis of triple-helical collagen can be controlled through $\mathrm{pH}$ adjustments of acid solutions which are brought to a neutral $\mathrm{pH}$ [5], likewise, it has been shown that adjustments in ionic strength can drive collagen fibrillary self-assembly process [4].

Calorimetric techniques represent suitable tools to monitor structural changes and biologically relevant events in protein conformation and self-assembly [14]. Isothermal titration calorimetry (ITC) is particularly useful in protein-related studies to address binding of small ligands, protein-protein interactions, drug targeting, supramolecular aggregation, and changes in enzymatic activity and inhibition, among others [15-18]. The enthalpy change of an interaction can be calculated using the raw ITC signal [14]. Interestingly, few studies have focused on the multi-step self-assembly process using ITC, for instance, Lakshminarayanan and coworkers studied the self-assembly of the protein Amelogenin and focused on studying the thermodynamic driving forces guiding supramolecular self-assembly through dilution experiments via ITC [19].

Herein we report the systematic study on the selfassembling fibrillogenic mechanism of type I collagen from rat tail tendons.

\section{Materials and methods}

\section{Type I collagen extraction}

Tendons were extracted from Wistar Hannover male specimens, provided by the Laboratorio de Ensayos Biológicos (LEBi, Universidad de Costa Rica, UCR). Approximately $1 \mathrm{~g}$ of the tendon was stirred in $200 \mathrm{ml}$ of $3 \%(\mathrm{v} / \mathrm{v})$ acetic acid solution for $24 \mathrm{~h}$ at $4{ }^{\circ} \mathrm{C}$. The resulting solution was filtered at room temperature with gauze and centrifuged at $4500 \mathrm{rpm}$ for $30 \mathrm{~min}$. The supernatant was lyophilized at $1.3 \mathrm{mbar},-20^{\circ} \mathrm{C}$, for $24 \mathrm{~h}$ (Martin Christ beta 1-8 LSC, Osterode am Harz, Germany). Inhouse extracted samples were compared against commercial type I collagen from cattle bovine purchased from Thermo Fisher Scientific (catalog number A1064401, Thermo Fisher Scientific).

\section{Type I collagen gelation}

Lyophilized collagen was dissolved in $3 \%(\mathrm{v} / \mathrm{v})$ acetic acid solution while adjusting the $\mathrm{pH}$ to $7.47 \mathrm{using} 1 \mathrm{~mol} /$ $\mathrm{L} \mathrm{NaOH}$. The solution was incubated overnight at $4{ }^{\circ} \mathrm{C}$ for gelation. The resulting gel was centrifuged and washed three times with ultrapure water $(18 \mathrm{M} \Omega / \mathrm{cm})$, dialyzed with a Spectra/Por 3 membrane $(32 \mathrm{~mm}$ diameter, $3.2 \mathrm{ml} / \mathrm{cm}$ volume), and stirred at $4{ }^{\circ} \mathrm{C}$ for over 4 days (solvent exchange took place every $2 \mathrm{~h}$ ). For nondialyzed collagen, these steps were omitted. Whenever collagen dry films were needed, the gel was dried out in an oven at $45^{\circ} \mathrm{C}$ for 4 days.

\section{Collagen characterization \\ Circular dichroism (CD)}

CD spectra were recorded using a J-815 spectropolarimeter (Jasco Corporation, Japan) at $20^{\circ} \mathrm{C}$ in a $10 \mathrm{~mm}$ path length cuvette in the far UV region (190-250 nm), with signal averaging over $3 \mathrm{~s}$ per $0.5 \mathrm{~nm}$ interval at a concentration of $0.2 \mathrm{mM}$. Two repeated scans were obtained, and the baseline spectra was subtracted from the average, and blank subtraction was performed for smoothing 
the spectra. CD data are expressed as molar ellipticity values [20].

Fourier-Transform infrared spectroscopy (FTIR). A Nicolet 6700 spectrophotometer equipped with an Attenuated Total Reflectance (ATR) sampling accessory was used, encompassing 4000 to $400 \mathrm{~cm}^{-1}$ wavenumbers with a standard resolution of $0.09 \mathrm{~cm}^{-1}$ and a scanning speed of $32 \mathrm{spectra} / \mathrm{s}$.

\section{Differential scanning calorimetry (DSC)}

Measurements were carried out on a TA Q200 instrument, using a temperature ramp of $10^{\circ} \mathrm{C} / \mathrm{min}$ with scans over the range of $20-200{ }^{\circ} \mathrm{C}$. Aluminum containers were used, and a typical sample mass of $5 \mathrm{mg}$.

\section{Amplitude modulated atomic force microscopy (AFM)}

Dry films of collagen were directly deposited on freshly cleaved mica substrates, and dried at room conditions overnight. Sample topography was analyzed in air using an AFM microscope (Asylum Research, Santa Barbara, USA), operated in tapping mode. Silicon probes (model Tap150Al-G), backside with resonance frequencies of $150 \mathrm{kHz}$ and force constant of $5 \mathrm{~N} / \mathrm{m}$ were used.

\section{Scanning electron microscopy (SEM)}

Samples were deposited on the sample holders as films and gold-coated before imaging. SEM images were obtained with a Hitachi TM-3000 tabletop microscope operating at $5 \mathrm{kV}$, using charge-up reduction (low vacuum) mode.

\section{Thermogravimetric analysis (TGA)}

Samples were analyzed using a Q500 TA Instruments. Samples (approx. $5 \mathrm{mg}$ ) were placed in standard platinum pan, and mass loss change was monitored between 50 and $1000{ }^{\circ} \mathrm{C}$.

Dynamic Mechanical Thermal Analysis (DMTA). Thermo-mechanical properties of collagen samples were determined at $25^{\circ} \mathrm{C}$ using a Q500 (TA Instruments) instrument, with a testing strain of $10 \%$, a $65-\mathrm{mm}$ gap load, a $4.5 \mathrm{~mm}$ clamp face and a $16.66 \mu \mathrm{m} / \mathrm{s}$ gap speed. Tensile specimen dimensions were $4.5-5 \mathrm{~mm}$ width, $27-$ $29 \mathrm{~mm}$ length and 1-1.6 $\mathrm{mm}$ thickness.

\section{Isothermal titration Calorimetry (ITC)}

ITC experiments were performed with a NanoITC2G (T.A. Instruments, USA). A sodium hydroxide solution $(4.6 \mu \mathrm{M}$ in ultrapure water) was titrated over aqueous type I collagen $(0.2 \mathrm{mg} / \mathrm{mL}$ in $0.33 \% \mathrm{v} / \mathrm{v}$ acetic acid). A volume of $950 \mu \mathrm{L}$ of the collagen solution was loaded in the cell and titrated with 24 titrant aliquots, temperature was kept constant at $30.0 \pm 0.1^{\circ} \mathrm{C}$ during the experiments, and the system was continuously stirred (300 rpm) with the syringe. Blank experiments were carried out by titrating $0.33 \%(\mathrm{v} / \mathrm{v})$ acetic acid solutions with the corresponding $\mathrm{NaOH}$ titrant. All experiments were carried out at least in triplicate.

\section{Results}

Figure 1 presents FTIR spectra of extracted freeze-dried collagen samples before and after dialysis. Table 1 shows the peak centered values obtained for the Amide A, Amide B, and Amide I. Typical signals from type I collagen were observed [21], the band extending from 1640 to $1670 \mathrm{~cm}^{-1}$ is attributed to Amide I [21, 22], originated by the stretching vibration of the amide carbonyl group [23, 24]. The band extending from 1600 to $\sim 1500 \mathrm{~cm}^{-1}$ is attributed to Amide II [21], it correlates the C-N stretching and the N-H bending [25]. An Amide III band was found centered at $1250 \mathrm{~cm}^{-1}$ [6], as a result of the bending of the $\mathrm{N}-\mathrm{H}$ group and vibrational stretching of $\mathrm{C}-\mathrm{N}$ [26]. Amide $\mathrm{V}$ bands tend to appear at a low frequency ranges from 575 to $775 \mathrm{~cm}^{-1}$, in this case it was found at $650 \mathrm{~cm}^{-1}$. This band is associated to the N-H bond's wave motion and mainly to the $\mathrm{CH}_{2}$ vibrations (this band was absent in non-dialyzed collagen samples) [27].

Dialyzed samples exhibited characteristic type I collagen bands, such as Amide A around $3400 \mathrm{~cm}^{-1}$ (involving $\mathrm{N}-\mathrm{H}$ stretching along with the hydrogen bonds) as well as an Amide B (visible near $2900 \mathrm{~cm}^{-1}$, involving the symmetric stretching of $\mathrm{CH} 2$ groups) [21].

Clear differences between dialyzed and non-dialyzed samples were found. Non-dialyzed collagen spectra showed two pronounced bands at $1540 \mathrm{~cm}^{-1}$ and $1410 \mathrm{~cm}^{-1}$, these bands indicate the presence of sodium acetate traces (representative bands at $1560 \mathrm{~cm}^{-1}$ and $1413 \mathrm{~cm}^{-1}$ ) produced by the neutralization of acetic acid by $\mathrm{NaOH}[28,29]$, this salt is likely to remain adsorbed onto collagen self-assembled fibrils. The bands related to the C-O bond, at $1090 \mathrm{~cm}^{-1}$ and $800 \mathrm{~cm}^{-1}$, are more intense in non-dialyzed collagen samples dialysis due to presence of sodium acetate.

Circular dichroism was used for investigating the structural characterization of extracted type I collagen in solution. Figure 2 presents the CD spectra of extracted dialyzed collagen, the strong negative band centered around $200 \mathrm{~nm}[30,31]$ is an indication of the canonical triple helix (TH) structure [32, 33].

Denaturation temperature of freeze-dried collagen samples was found to be $75^{\circ} \mathrm{C}$, meanwhile dialyzed and non-dialyzed samples denatured at $84{ }^{\circ} \mathrm{C}$ and $83^{\circ} \mathrm{C}$ respectively.

Figure 3 shows an endothermic denaturation temperature of $84^{\circ} \mathrm{C}$ for non-dialyzed collagen, which corresponds to the unfolding of the TH structures [34], the endothermic event observed in this sample at $60^{\circ} \mathrm{C}$ is associated to the melting of traces of sodium acetate hydrate [35]. This event is absent in the dialyzed 

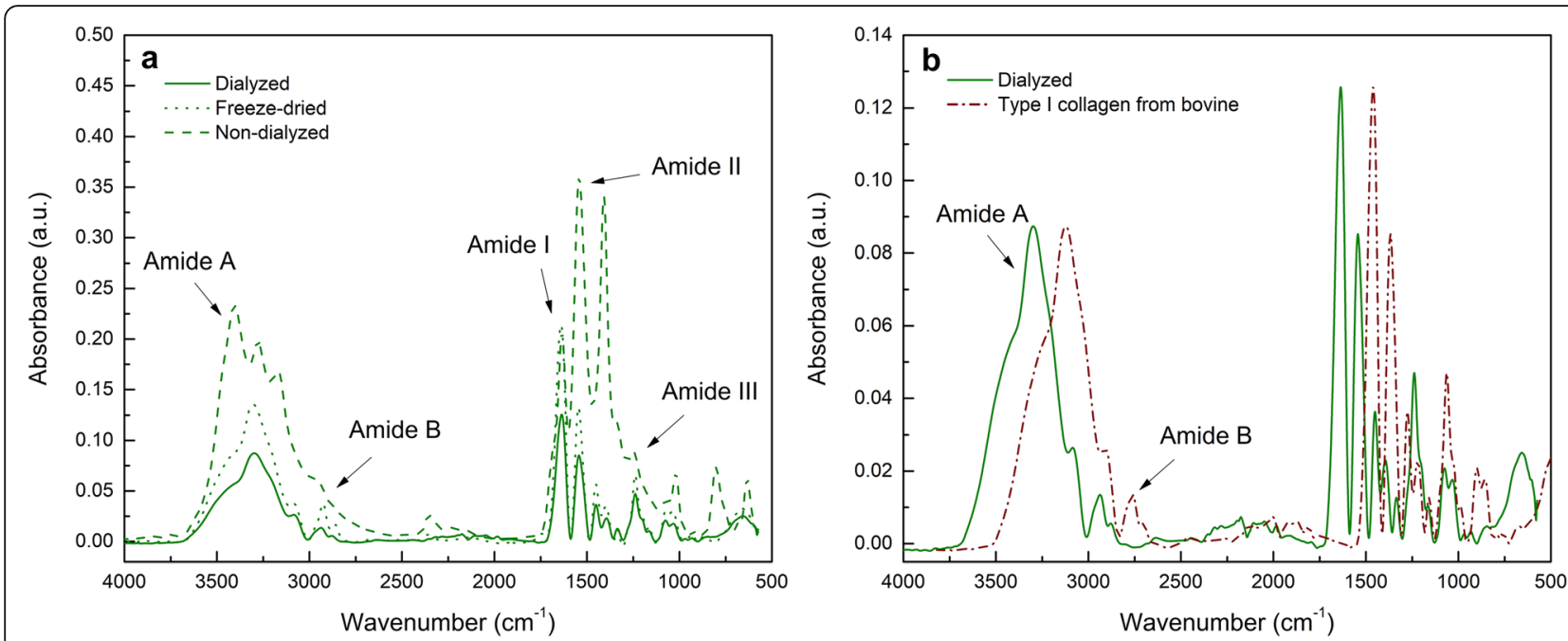

Fig. 1 FTIR spectra corresponding to a) Extracted rat tail tendon type I collagen samples (freeze-dried, dialyzed, and non-dialyzed respectively), and b) Commercial type I bovine collagen versus dialyzed extract

collagen thermogram, indicating that dialysis treatment was effective at removing salt traces from extracted type I collagen samples.

The morphological and mechanical characterization of self-assembled collagen was carried out using SEM and AFM. Representative scanning electron microscopy (SEM) images corresponding to non-dialyzed (Fig. 4a) and dialyzed collagen samples (Fig. 4b). Though microfibers are observed in both cases, non-dialyzed collagen clearly shows sodium acetate crystals, thus confirming that the endothermic event observed on DSC analyses at $60^{\circ} \mathrm{C}$ is in fact associated with this salt. Self-assembled samples were also analyzed using atomic force microscopy (AFM) and the results are shown in Fig. 4c-e. Figure $4 \mathrm{c}$ shows the collagen microfibers and nanofibrils in more detail [6], the nanofibrils have a D-pattern of $65 \pm$ $1 \mathrm{~nm}$. Figure 4d shows the phase image contrast (which is associated with the voids formed between each fibril and the changes in adhesion forces between and the surface), as the AFM tip is not able to reach the bottom of these voids it interacts differently than on the fibril surface $[4,32,33]$. Each fibril diameter varies between 450 and $900 \mathrm{~nm}$, which is in agreement with the reported value for the tendons fibrils up to $1 \mathrm{~cm}$ long and $500 \mathrm{~nm}$ in diameter [36].
Stress-strain curves of both samples are shown in Fig. 5. Non-dialyzed collagen exhibited a maximum tensile strength of $9.06 \mathrm{MPa}$, much higher than the strength obtained for the dialyzed collagen, of 2.38 $\mathrm{MPa}$ (Fig. 5a). Extracted samples exhibited degradation temperature ranges from $280^{\circ} \mathrm{C}$ to $500^{\circ} \mathrm{C}$ approximately, similar values were obtained for bovine cattle type I collagen. No high amount of impurities were detected since less than $10 \mathrm{wt} . \%$ degraded between 100 and $250^{\circ} \mathrm{C}$ and the residues is less than 10 wt.\% (Fig. 6b).

A detailed study of the collagen fibrillogenic mechanism was carried out using ITC. Initially, the neutralization reaction between acetic acid and $\mathrm{NaOH}$ and the collagen dissolution with acetic acid was studied. Representative ITC enthalpograms are shown in Fig. $6 \mathrm{a}$ and $\mathrm{b}$ respectively. As type I collagen was dissolved in acetic acid aqueous solutions dropwise addition of sodium hydroxide did neutralize the acid, formed a buffer system, and eventually brought up $\mathrm{pH}$ values above collagen's isoelectric point (pI).

Panels c and d from Fig. 6 show ITC enthalpograms corresponding to $\mathrm{NaOH}$ titration of dialyzed extracted collagen and denatured collagen (gelatin), respectively. Both titrations exhibited high initial energy release due as a

Table 1 FTIR peak centered values of amide bonds $\left(\mathrm{cm}^{-1}\right)$ and intensity ratio of Amide A $\left(\mathrm{cm}^{-1}\right) /$ Amide I $\left(\mathrm{cm}^{-1}\right)$

\begin{tabular}{lllll}
\hline Sample & Amide A & Amide B & Amide I & Amide A/Amide I \\
\hline Type I collagen from bovine & 3122 & 2761 & 1459 & 0.69 \\
Dialyzed & 3297 & 2937 & 1635 & 0.69 \\
Non-dialyzed & 3278 & 2967 & 1635 & 0.96 \\
Freeze-dried & 3303 & 2925 & 1639 & 0.63 \\
\hline
\end{tabular}




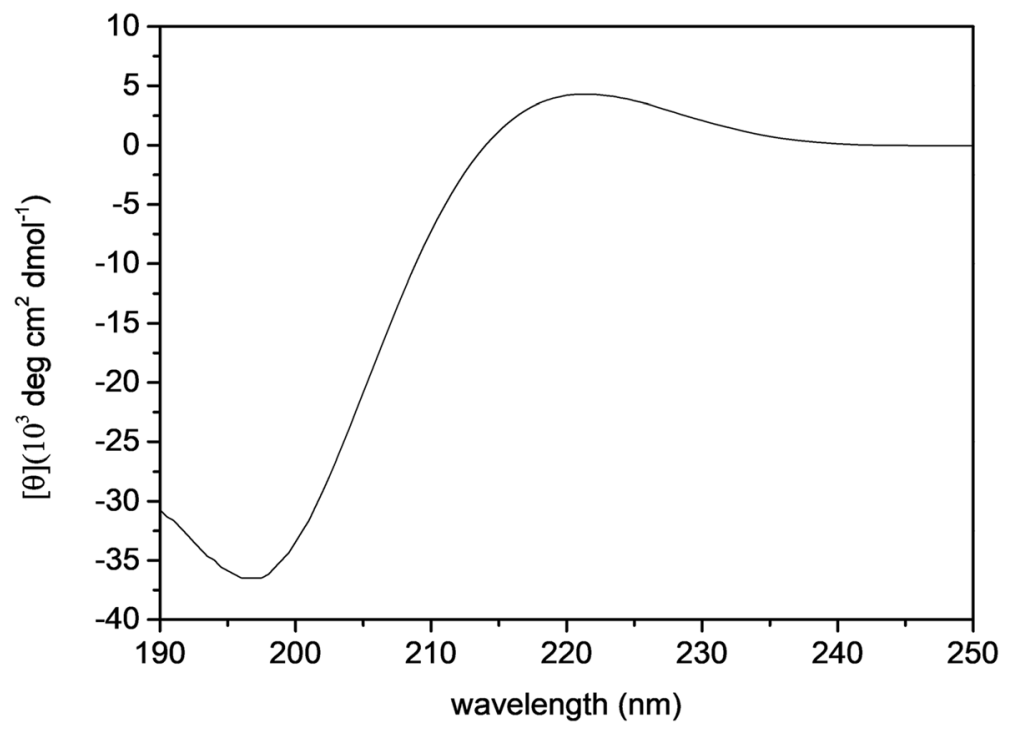

Fig. 2 Circular dichroism (CD) spectra of a representative dialyzed rat tail tendon type I collagen sample

result of the abovementioned neutralization reaction. $\mathrm{Cu}$ mulative additions of $\mathrm{NaOH}$ aliquots increase both $\mathrm{pH}$ and ion concentration of both systems, and both collagen titrations (panels c \& d) consumed a higher amount of $\mathrm{NaOH}$ compared to the control acetic acid titration (panel a).

Figure $7 \mathrm{a}$ shows enthalpy values corresponding to the titration of extracted type I collagen with either $\mathrm{NaCl}$ and sodium acetate solutions. Figure 7b depicts collagen $\mathrm{pH}$ changes and self-assembly progression as a function of $\mathrm{NaOH}$ addition. Figure 7c shows that at its isoelectric point collagen was self-assembled with an associated enthalpy value of $3.28 \mathrm{~J} / \mathrm{mol}$ [4].

\section{Discussions}

FTIR studies were carried out in order to confirm the chemical identity of extracted collagen samples before and after dialysis. The bands for the non-dialyzed are shifted in comparison to the Amide bands of dialyzed collagen. This shifting could be associated with the contributions of other proteins. The non-assembled freezedried collagen bands are also shifted, which might originate from conformational transitions in the selfassembled structure [6]. The differences between the peak centered values of collagen from bovine and rat tail tendons are associated with differences in the $\mathrm{N}$ - and $\mathrm{C}$ -
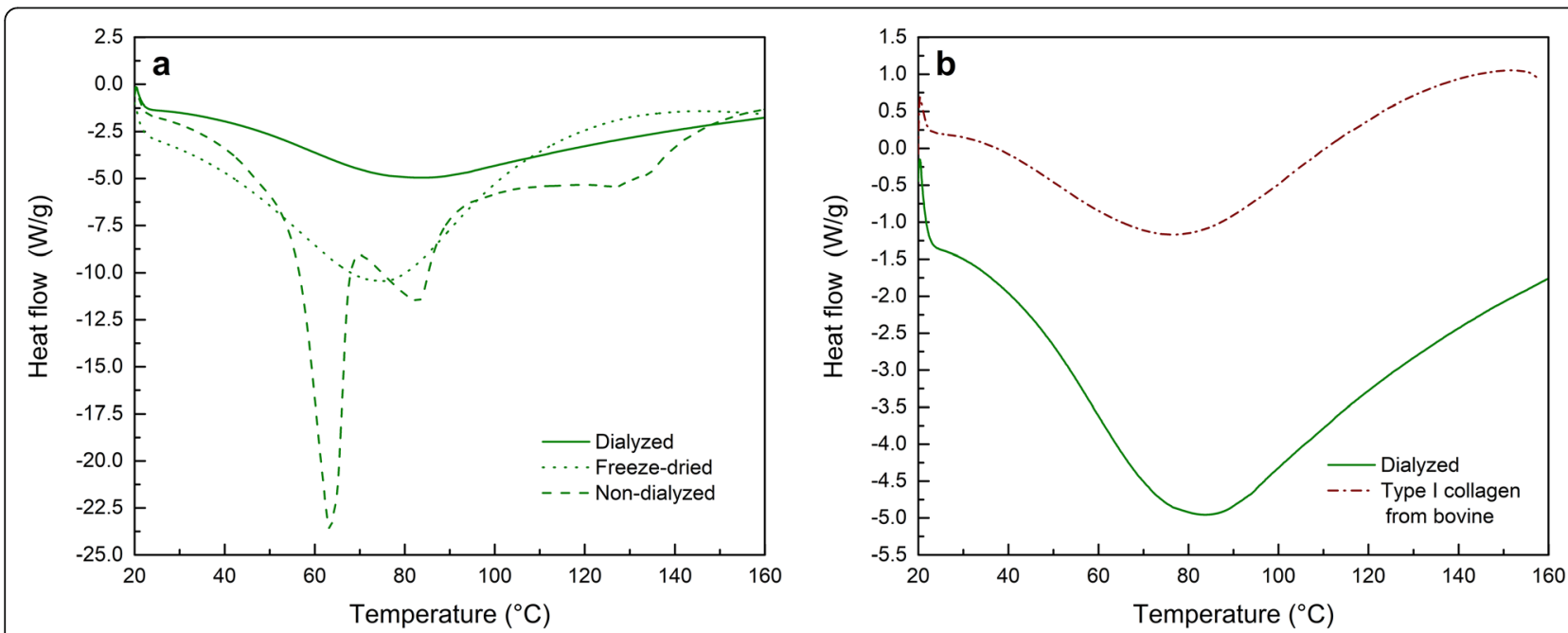

Fig. 3 Differential scanning calorimetry (DSC) determinations on extracted and commercial collagen samples. a DSC thermograms of extracted rat tail tendon type I collagen at different assembly conditions: freeze-dried, self-assembled non-dialyzed, and self-assembled dialyzed. b DSC thermograms of type I collagen from rat tail and cattle bovine (endothermic down, exothermic up) 



Fig. 4 Morphological studies on self-assembled extracted collagen samples. a Scanning electron microscopy (SEM) images of a non-dialyzed collagen sample, and $\mathbf{b}$ ) a dialyzed collagen sample. c Atomic force microscopy (AFM) topography image of dialyzed collagen, d) AFM phase image, and e) Line profile (as shown in panel $\mathbf{d}$ corresponding to the sample from panel c)

terminus globular domains, glycosylation, and triplehelical domains [37].

Circular dichroism (CD) investigations were carried out to assess secondary structure of extracted type I collagen in solution [38, 39]. The canonical triple helix $(\mathrm{TH})$ structure was confirmed $[40,41]$. This $\mathrm{TH}$ structure is a major structural pattern observed in collagen [42], consisting of three supercoiled polyproline II Helices (ppII) formed by amino acid residues arranged in repeated X-Y-Gly triads, where X, Y are often lproline (Pro) and 4R-hydroxy-l-proline (4R-Hyp), respectively. Hydroxylation of Pro in the $\mathrm{Y}$ position is
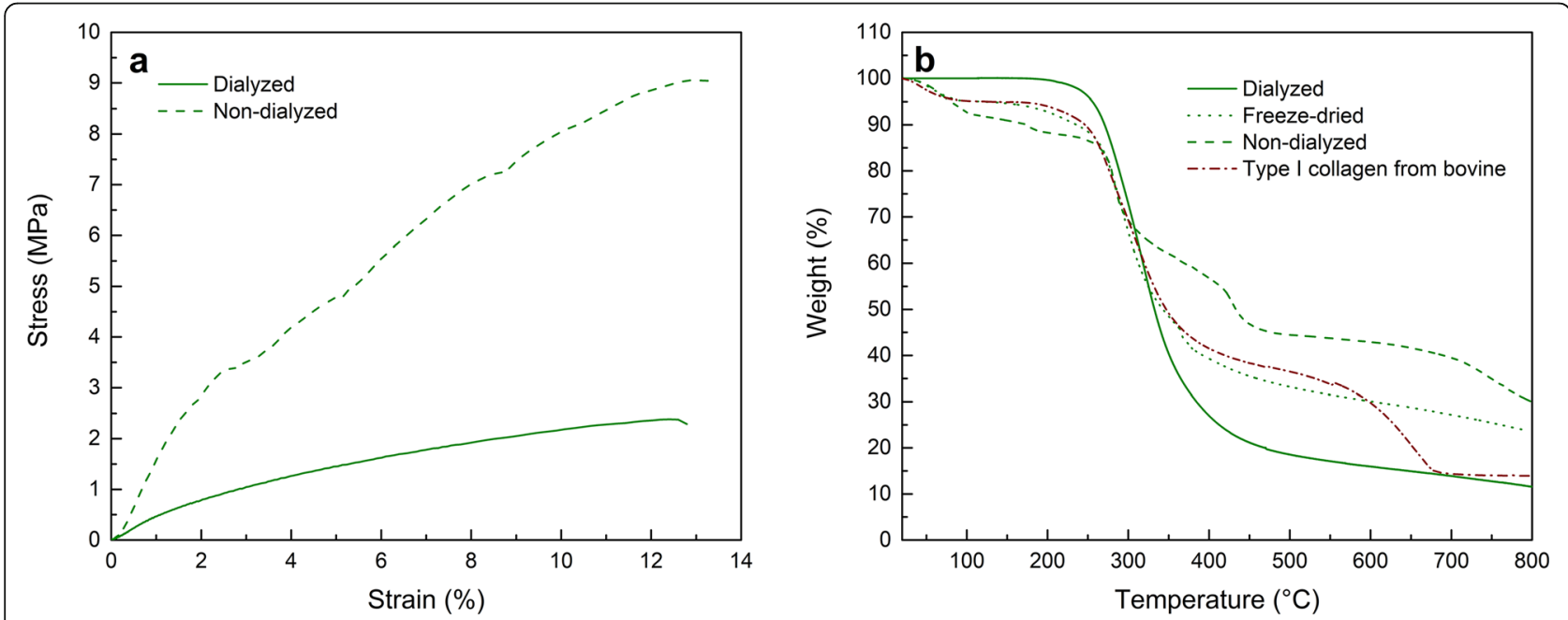

Fig. 5 Mechanical and thermogravimetric analysis of collagen samples. a Stress-strain curve of dialyzed and non-dialyzed self-assembled type I collagen. b Thermogravimetric (TGA) thermograms of dialyzed extracted collagen and type I collagen from cattle bovine 

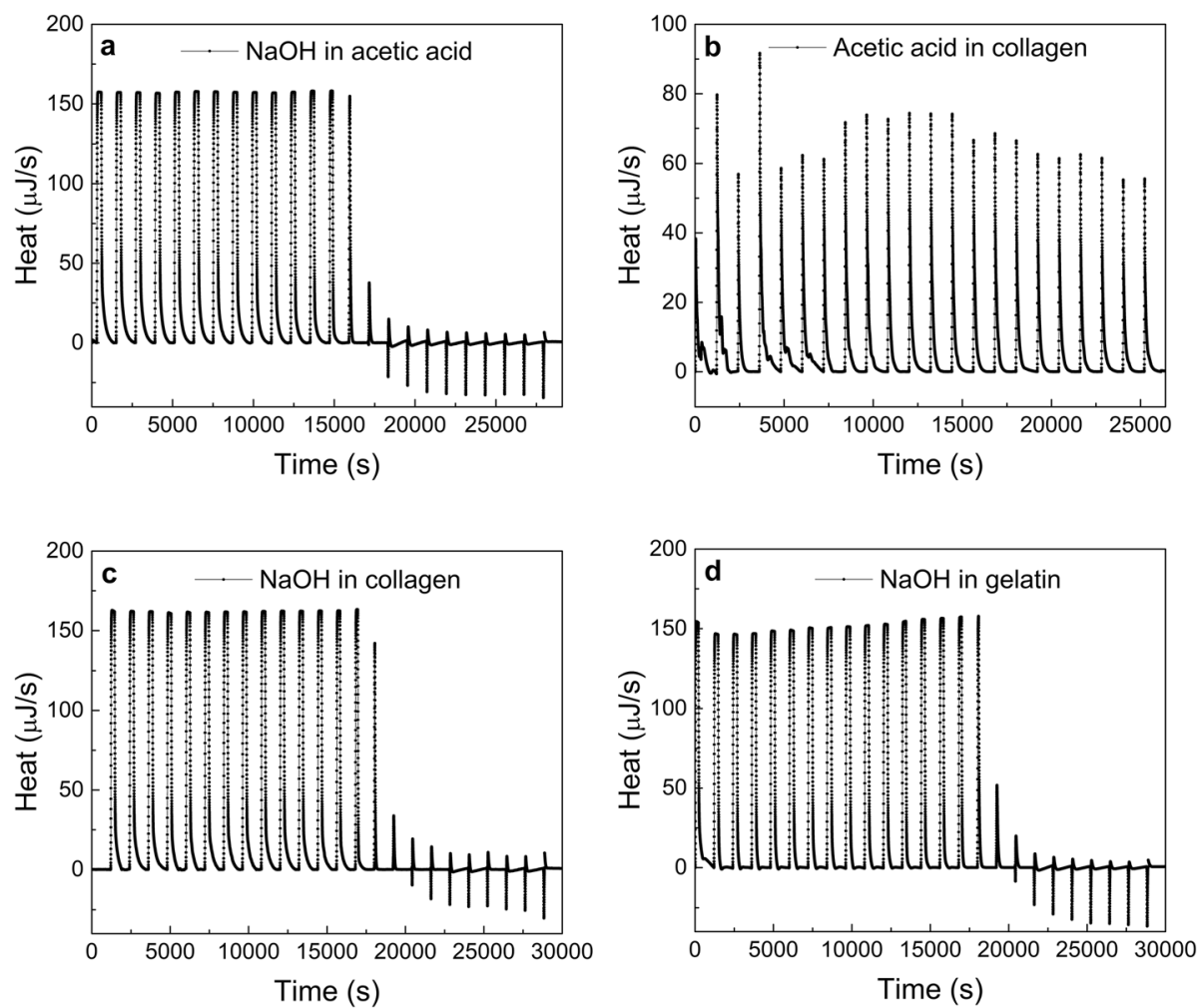

Fig. 6 Representative ITC enthalpograms. a Acetic acid titration with $\mathrm{NaOH}$, titration used as a control. b Dialyzed extracted collagen titration with acetic acid, titration used as a control. c Dialyzed extracted collagen titration with $\mathrm{NaOH}$. d Denatured collagen titration with $\mathrm{NaOH}$ ([collagen] $=0.2 \mathrm{mg} / \mathrm{mL}$, in $0.33 \%(\mathrm{v} / \mathrm{v})$ acetic acid, $[\mathrm{NaOH}]=4.6 \mu \mathrm{M})$

essential to the fold and stabilization of $\mathrm{TH}$ [43], in which about $10 \%$ of the amino acids are 4R-Hyp [42].

Differential Scanning Calorimetry (DSC) studies were carried out to assess the effect of dialysis treatment on the selfassembling capacities of extracted type I collagen samples.

The results suggest that dialysis did not interfere significantly with microfibers and nanofibrils formation capacities, as both dialyzed and non-dialyzed collagen samples exhibited quite similar denaturation temperatures.

Differences between freeze-dried and self-assembled collagen samples can be rationalized in terms of supramolecular interactions between adjacent triple helixes in both cases. Self-assembled collagen microfibrillar structures are composed of several THs interacting via hydrogen bonds and forming highly organized and hierarchical microfibers. In contrast, THs present in freeze-dried collagen happen to be far more unordered, thus requiring less energy to unfold and denature as a consequence [44]. Furthermore, freezing might induce destabilization of collagen due to expansion of hydrated collagen fibrils, this might cause additional mechanical stress as well as changes in the corresponding denaturation temperature [45].

Microscopy studies were carried in order to assess any differences in fibrillogenic capacities of non-dialyzed and dialyzed collagen samples. Dialyzed collagen samples (Fig. $4 \mathrm{~b})$ indicate a notorious morphological organization due to the dialysis treatment. Single microfibers formed by self-assembly of nanofibrils were observed. The D-pattern matches similar values to the reported in the literature [4, $32,33]$. The microscopic and TGA analysis suggests a low amount of impurities remained in the extracted material since less than $10 \mathrm{wt} . \%$ degraded between 100 and $250{ }^{\circ} \mathrm{C}$ and the residues is less than $10 \mathrm{wt. \%}$ (Fig. 5b).

Mechanical studies were carried in order to assess any differences between non-dialyzed and dialyzed collagen samples. Both samples exhibited characteristic nonlinear elastic behaviors, a response likely attributed to straightening of the $\mathrm{TH}$ conformation structures [46] and the alignment of both $\mathrm{N}$ - and $\mathrm{C}$ - terminus ends [47]. The higher tensile strength of the non-dialyzed collagen is most likely associated with the salt presence that confers greater rigidity to the collagen, through noncovalent salt bridges that act as cross-linking points. This in turn makes the molecules more rigid, since relaxation movements are disabled, thus increasing overall tensile strength [48]. The determination of the stressstrain relationships of individual collagen fibrils is important to understand the mechanical properties of tissues structure as well as skin, tendon, and bone. 

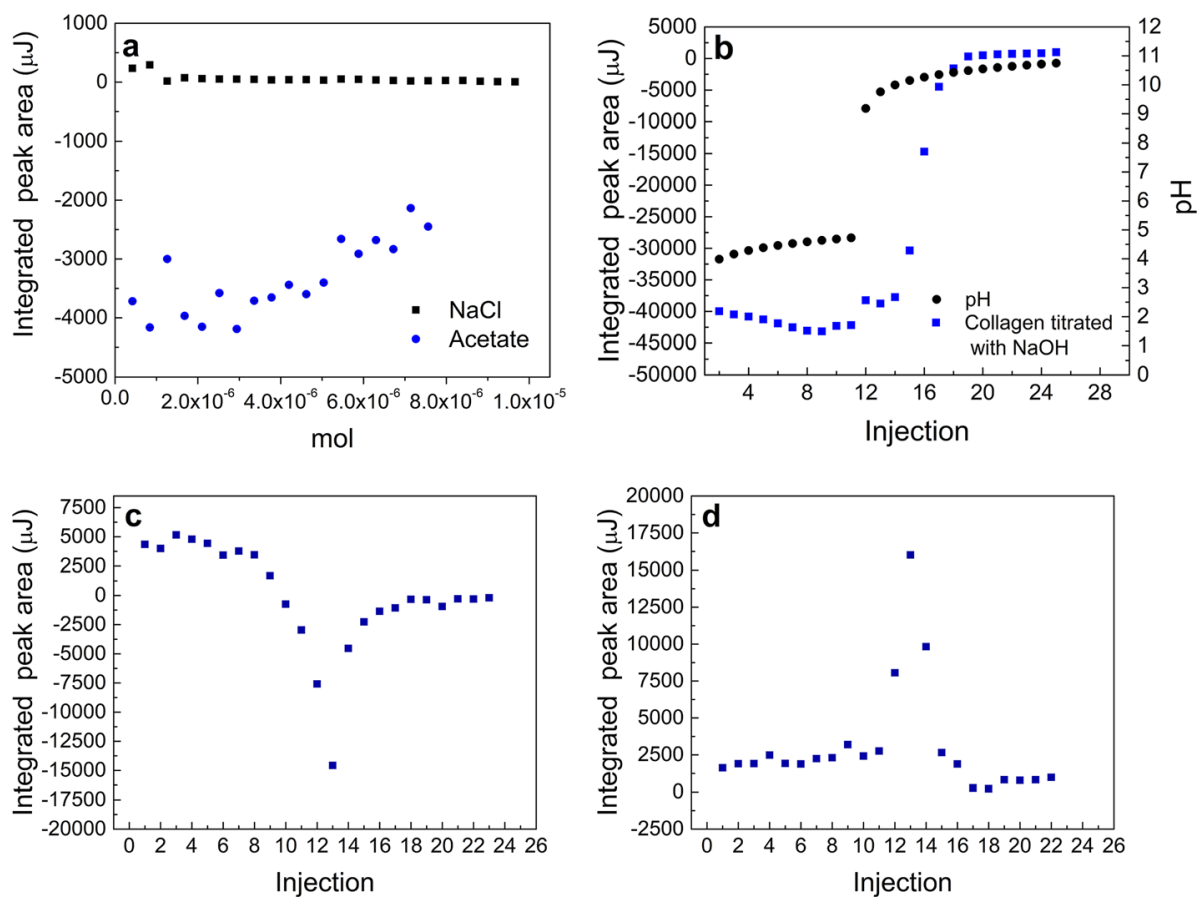

Fig. 7 Collagen self-assembly assessment via ITC titrations. a Assessment of salting effect. Integrated area corresponding to the addition of $\mathrm{NaCl}$ (black traces) and sodium acetate (blue traces) into $\mathrm{NaOH}$. $\mathbf{b}$ Integrated area corresponding to the addition of $\mathrm{NaOH}$ into dialyzed collagen in acetic acid (blue traces), this panel also depicts $\mathrm{pH}$ values measured under equivalent conditions to the ones from the respective titration. $\mathbf{c}$ Corrected area corresponding to extracted collagen in acetic acid $\mathrm{NaOH}$ titration. $\mathbf{d}$ Corrected area corresponding to denatured collagen in acetic acid $\mathrm{NaOH}$ titration ([collagen] $=0.2 \mathrm{mg} / \mathrm{mL}$, in $0.33 \%(\mathrm{v} / \mathrm{v}$ ) acetic acid, $[\mathrm{NaOH}]=4.6 \mu \mathrm{M}$ ). Integrated areas were corrected by subtracting the heat of associated to the acid-base control titration

ITC experiments were carried out in order to gain better insights of the fibrillogenic mechanism of dialyzed type I collagen samples. It was hypothesized that ITC titrations might help to identifying the factors and conditions that drive collagen macromolecular units to adopt a specific secondary conformation, which eventually lead to hierarchical formation of higher-order structures. In this fashion, type I collagen self-assembly was triggered by controlled $\mathrm{pH}$ increasing resulting from addition of sodium hydroxide as a titrant.

As type I collagen was dissolved in acetic acid aqueous solutions dropwise addition of sodium hydroxide did neutralize the acid, formed a buffer system, and eventually brought up $\mathrm{pH}$ values above collagen's isoelectric point (pI). Collagen's self-assembly shows dependence of $\mathrm{pH}$, temperature, and protein concentration, in our ITC experiments temperature remained constant at $30.0 \pm 0.1^{\circ} \mathrm{C}$, and protein concentration was higher than the minimal critical concentration for assembly [49].

Initially, control titrations of sodium hydroxide were carried out for calibration [50] as shown in Fig. 6a. Initial exothermic peaks (up) correspond to the expected neutralization reaction, while further endothermic signals can be attributed to dilution of titrant excess once the neutralization is completed. Figure $6 \mathrm{~b}$ shows a control enthalpogram corresponding to dialyzed extracted collagen titrated with acetic acid, virtually constant exothermic peaks are an indication of the dilution of acetic acid into collagen solution with little effect on the protein conformation and self-assembly in solution.

Furthermore, higher heat release was observed on both collagen titrations compared to the control acetic acid one. This heat release difference can be rationalized in terms of a number of simultaneous molecular events taking place on collagen side chains as $\mathrm{pH}$ increases, including neutralization of positively charged amino acids by hydroxyl ions, resulting in changes in the electrostatic protein equilibrium, and triggering conformational changes that lead to cooperative fibrillogenesis in the last place.

Two additional experiments were carried out in order to determine whether energy release or absorption were dominated by aggregation due to a salting in or salting out effect, rather than the molecular interactions involving proton exchange leading hierarchical assembly.

$\mathrm{NaCl}$ values remained virtually constant along the experiment, though acetate ions had more important variations most likely due to their acid-base capacity and their well-known kosmotropic effect according to the Hoffmeister series. 
These enthalpy values are both a combination of the ions dilution enthalpy and their interaction with collagen units and acetic acid, and they appear way smaller than those originated by the addition of $\mathrm{NaOH}$ (see Fig. $6 \mathrm{c} \&$ d). Even though events like interactions between charged macromolecules, Debye-Hückel screening effects, and changes in water activity values are likely to take place in this scenario [51], this result suggests that energy release or absorption was driven by intermolecular interactions and is not due to collagen precipitation related to high ionic strength values.

$\mathrm{THs}$ of collagen can pre-assembly at $\mathrm{pH}$ values lower than the protein's pI, consequently, detected heat release at lower $\mathrm{pH}$ values is associated to neutralization, assembly, and dissolution processes [52]. the steepest increase in corrected $\Delta \mathrm{H}$ was observed at a $\mathrm{pH}$ value of 6.5 , this increase is associated to higher energy release values than those obtained for the injection of acetate solutions into acetic acid (as depicted in Fig. 7a), demonstrating that this increase is not only due to dilution effects but also to changes in ionic strength. Presence of pronounced fibrillar type I collagen structures has been confirmed via AFM studies by Jiang and co-workers. This study assessed the morphology of collagen self-assembled structures at $\mathrm{pH}$ values ranging 2.5 to 10.5 at a fixed electrolyte concentration, finding the presence of elongated globules between $\mathrm{pH} 2.5$ and 3.5, though finding fibrils in the 5.5-9.5 range [4]. To determine whether this high energy release at the isoelectric point was due to fiber self-assembly the same neutralization process was carried out using denatured collagen (gelatin) as a control. Gelatin also presented a sharp increase of a similar magnitude at its $\mathrm{pI}$, though the process happened to be endothermic, a presumptive indicative of a different aggregation pathway (Fig. 7d). Type I collagen fibrillogenesis is a multi-step process driven by the increase in entropy associated with increasing molecular disorder at the water-protein interface [12]. Its nucleation growth mechanism has been reported to be driven by a polymerization reactions, starting from the monomer and made possible by the presence of covalently crosslinked oligomers [49], additionally, both hydrophobic and ionic interfibrillar interactions taking place [53], polar amino acid residues seek to establish hydrogen bonds with solvent molecules creating transient $\alpha$-helices and $\beta$-sheets [54].

To form the gelatin, it is necessary to break up the secondary and higher structures of the parent protein collagen, with varying degrees of hydrolysis of the polypeptide backbone [55], from a random crosslinking of primary chains, locally twisted together, so the aggregation process can be hydrophobic effect-driven as well [56].

\section{Conclusions}

There is no doubt that collagen-based materials are keystones as regenerative medicine constructs. In this work we provide thorough evidence that purification steps are key to define further mechanical and thermal properties of self-assembled materials based on type I collagen. Thermal analyses evidenced the importance of dialysis steps in removing salt impurities from collagen matrixes as differences in denaturation temperature were observed. In addition, it was found that salt traces can improve tensile strength of collagen-based materials.

ITC proved to be a reliable technique for studying collagen fibrillogenesis in solution state. It allowed to determine that this multi-step self-assembly process starts from $\mathrm{pH} 4.4$, with an associated enthalpy of selfassembly of $3.27 \pm 0.85 \mathrm{~J} / \mathrm{mol}$. Since it is so complex to understand biomolecular interactions, using ITC provided a complete heat aggregation profile of collagen fibrillogenesis. It also enabled the study of some of the factors influencing self-assembly like $\mathrm{pH}$, and presence of salts. Even though ITC analysis can provide vast information regarding the fundamentals of this phenomenon there is still plenty of work to do regarding the thermodynamics and kinetics of this multi-set fibrillogenic process.

There is no doubt that consideration of collagen structure and chemistry will remain a promising area for further study. Once these details are elucidated, control over collagen self-assembly process can be exerted in order to obtaining collagenous constructs with adjustable and functional performance using different extracellular molecules that can influence its assembly at different chemical enviroments, thus determining distinctive cellular responses [14], like heart valves, ligaments and tendons, nerves, cartilage, meniscus, and blood vessels, or great use in regenerative medicine and tissue engineering applications.

\section{Abbreviations}

FTIR: Fourier-transform infrared spectroscopy; CD: Circular dichroism: pl: Isoelectric point; SEM: Scanning electron microscopy; AFM: Amplitude modulated atomic force microscopy (AFM).; TGA: Thermogravimetric analysis; DSC: Differential calorimetry

\section{Acknowledgements \\ This work was financially supported by National center of High Technology of Costa Rica CeNAT-CONARE and Instituto Tecnológico de Costa Rica.}

\section{Authors' contributions}

J.G.-M., J.M.C.-S., J.R.V.-B., and R.J.G.-P. planned the research; S.G.-C. provided the rat tails for collagen extraction; and J.G.-M. prepared all the samples and performed most of the analysis with contributions from R.J.G.P. S:G did and analyzed the CD measurements. C.R.-G did the FTIR, DSC and TGA of the bovine collagen. Y.R.C.-U. helped with the AFM measurements. S J.G.-M prepared the manuscript with contributions from R.J.G.-P., Y.R.C.-U., J.M.C.-S., R. L and, J.R.V.-B. Y.R.C.-U and C.R.-G did the critical reviews of the manuscript. C.R.-G revised the English writing. All authors have read and agreed to the published version of the manuscript. 


\section{Availability of data and materials}

All data generated and analyzed during the current study are available from the corresponding author on reasonable request.

\section{Ethics approval and consent to participate}

The animal proceedings were in compliance with local legislation (Ley de Bienestar de los Animales $N^{\circ} 7451$ ) and approved by the Comité Institucional de Cuido y Uso de Animales (CICUA) from the Universidad de Costa Rica (CICUA 10-2000). We used the maximum amount of animals authorized by CICUA based on the $3 R^{\prime}$ s principles.

\section{Consent for publication}

Not applicable.

\section{Competing interests}

The authors declare that they have no competing interests.

\section{Author details}

'Escuela de Ciencia e Ingeniería de los Materiales, Instituto Tecnológico de Costa Rica, Cartago 159-7050, Costa Rica. ${ }^{2}$ Instituto de Investigación Interdisciplinar en Ciencias Biomedicas SEK (I3CBSEK), Facultad de Ciencias de la Salud, Universidad SEK, Fernando Manterola 0789, 7500000 Santiago, Chile. ${ }^{3}$ Biological Assays Laboratory (LEBi), Universidad de Costa Rica, San Pedro de Montes de Oca, San José, Costa Rica. ${ }^{4}$ National Nanotechnology Laboratory, National Center for High Technology (LANOTEC-CeNAT-CONARE), 1174-1200, Pavas, San José, Costa Rica. ${ }^{5}$ National University of Costa Rica, UNA, 86-3000 San José, Heredia, Costa Rica.

\section{Received: 22 July 2020 Accepted: 21 October 2020}

Published online: 23 November 2020

\section{References}

1. Moore L. AFM analyses of collagenous tissue; 2012

2. Xiong X, Ghosh R, Hiller E, Drepper F, Knapp B, Brunner H, Rupp S. A new procedure for rapid, high yield purification of type I collagen for tissue engineering. Process Biochem. 2009;44:1200-12.

3. Hedegaard CL, Collin EC, Redondo-Gómez C, Nguyen LTH, Woei Ng K, Castrejón-Pita AA, Castrejón-Pita JR, Mata A. Hydrodynamically Guided Hierarchical Self-assembly of Peptide-Protein Bioinks. Advanced Functional Materials. 2018;XXVIII(16):1-52.

4. Jiang F, Horber $\mathrm{H}$, Howard J, Muller D. Assembly of collagen into microribbons: effects of pH and electrolytes. J Struct Biol. 2004;148:268-78.

5. Roveri N, Falini G, Sidoti M, Tampieri A, Landi E, Sandri M, Parma B. Biologically inspired growth of hydroxyapatite nanocrystals inside. Mater Sci Eng C. 2003;23:441-6.

6. Boryskina O, Bolbukh T, Semenov M, Gasan A, Maleev V. Energies of peptide-peptide and peptide-water hydrogen bonds in collagen: evidences from infrared spectroscopy, quartz piezogravimetry and differential scanning calorimetry. J Mol Struct. 2007:827:1-10.

7. Omireeni E, Siddiqi N, Alhomida A. Biochemical and histological studies on the effect. J Saudi Chem Soc. 2010;14:413-6.

8. Barnard K, Light ND, Sims TJ, Bailey AJ. Chemistry of the collagen cross-links. Origin and partial characterization of a putative mature cross-link of collagen. Biochem J. 1987;CCXLIV(2):303-9.

9. Chandrakasan G, Torchia D, Piez K. Preparation of intact monomeric collagen from rat tail tendon and skin and the structure of the nonhelical ends in solution. J Biol Chemestry. 1976;251(19):6062-7.

10. González-Masís J, Cubero-Sesin JM, Corrales-Ureña YR, González-Camacho S, Mora-Ugalde N, Baizán-Rojas M, Loaiza R, Vega-Baudrit JR, Gonzalez-Paz RJ. Increased Fibroblast Metabolic Activity of Collagen Scaffolds via the Addition of Propolis Nanoparticles. Materials. 2020;XIII(14):1-13.

11. Chorsi MT, Curry EJ, Chorsi HT, Das R, Baroody J, Purohit PK, llies H, Nguyen T. Piezoelectric Biomaterials for Sensors and Actuators. Adv Mater. 2019; $\mathrm{XXXI}(1): 1-15$.

12. Pawelec KM, Best SM, Cameron RE. Collagen: a network for regenerative medicine. J Mater Chem B. 2016;IV(40):1-16.

13. Zhang S. Emerging biological materials through molecular self-assembly. Biotechnol Adv. 2002;XX:321-39.

14. Kabiri M, Unsworth LD. Application of Isothermal Titration Calorimetry for Characterizing Thermodynamic Parameters of Biomolecular Interactions:
Peptide Self-Assembly and Protein Adsorption Case Studies. Biomacromolecules. 2014;XV(10):3463-73.

15. Liang $Y$. Applications of isothermal titration calorimetry in protein science. Acta Biochimica et Biophysica Sinica. 2008;XL(7):565-76.

16. Damian L. Isothermal Titration Calorimetry for Studying Protein-Ligand Interactions. Methods Mol Biol. 2013;MVIII:103-18.

17. Luke K, Apiyo D, Wittung-Stafshede P. Dissecting Homo-Heptamer Thermodynamics by Isothermal Titration Calorimetry: Entropy-Driven Assembly of Co-Chaperonin Protein 10. Biophys J. 2005;LXXXIX(5):3332-6.

18. Weber PC, Salemme R. Applications of calorimetric methods to drug discovery and the study of protein interactions. Curr Opin Struct Biol. 2003;XIII:115-21.

19. Lakshminarayanan R, Yoon I, Hegde BG, Daming F, Du C, Moradian-Oldak J. Analysis of Secondary Structure and Self-Assembly of Amelogenin by Variable Temperature Circular Dichroism and Isothermal Titration Calorimetry. Proteins. 2009;LXXVI(3):560-9.

20. Guzmán F, Marshall S, Ojeda C, Carvajal-Rondanelli PA. Inhibitory effect of short cationic homopeptides against gram-positive bacteria. J Pept Sci. 2003;19(12):792-800

21. Muyonga J, Cole C, Duodu K. Characterisation of acid soluble collagen from skins of young and. Food Chem. 2004;85:81-9.

22. Roy R, Boskey A, Bonassar L. Processing of type I collagen gels using. J Biomed Mater Res. 2009;93:843-51.

23. Vidal Bde C, Mello ML. Collagen type I amide I band infrared spectroscopy. Micron. 2011;42:283-9.

24. Yousefi M, Ariffin F, Huda N. An alternative source of type I collagen based on by-product with. Food Hydrocolloids. 2016;63:372-82.

25. de Campos Vidal B. Fluorescence, aggregation properties and FT-IR microspectroscopy of. Acta Histochemica. 2014;116:1359-66.

26. Barth A, Zscherp C. What vibrations tell us about proteins. Q Rev Biophys. 2002;35(4):369-430

27. Fontaine-Vive F, Merzel F, Johnson M, Kearley G. Collagen and component polypeptides: low frequency and amide vibrations. Chem Phys. 2009;355:141-8.

28. Agasti N, Kaushik N. One pot synthesis of crystalline silver nanoparticles. Am Nanomaterials. 2014;2(1):4-7.

29. Libro del Web de Química del NIST, "Acetic acid, sodium salt," Secretary of Commerce on behalf of the United States of America, 2008. [Online]. Available: http://webbook.nist.gov/cgi/cbook.cgi?ID=B6005784\&Mask=80\#IRSpec. Accessed 13 Oct 2016.

30. Pati F, Adhikari B, Dhara S. Isolation and characterization of fish scale collagen of higher thermal stability. Bioresour Technol. 2010;101(10):3737-42.

31. Usha R, Ramasami T. Structure and conformation of intramolecularly crosslinked collagen. Colloids Surf B: Biointerfaces. 2005;41(1):21-4.

32. Minary M, Feng M. Nanomechanical heterogeneity in the gap and overlap regions of type I collagen fibrils with implications for bone heterogeneity. Biomacromolecules. 2009;10:2565-70.

33. Fang $M$, Banaszak M. Variation in type I collagen fibril nanomorphology. BoneKEy Rep. 2013;2(394):1-7.

34. Shoulders M, Raines R. Collagen structure. Annu Rev Biochem. 2009;78:929-58.

35. Johansen J, Dannemand M, Kong W, Fan J, Dragsted J, Furbo S. Thermal conductivity enhancement of sodium acetate trihydrate by. Energy Procedia. 2015;70:249-56.

36. Baldwin S, Quigley A, Clegg C, Kreplak L. Nanomechanical mapping of hydrated rat tail tendon collagen I fibrils. Biophys J. 2014;107:1794-801.

37. Belbachir K, Noreen R, Gouspillou G, Petibois C. Collagen types analysis and differentiation by FTIR spectroscopy. Analytical and Bioanalytical Chemistry. 2009;CCCXCV:829-37.

38. Ramamourthy G, Park JS, Seo CH, Park Y. Applications of circular Dichroism for structural analysis of gelatin and antimicrobial peptides. Int J Mol Sci. 2012;13(3):3229-44.

39. Johnson WC. Analyzing protein circular dichroism spectra for accurate secondary structures. Proteins Struct Funct Bioinform. 1999;35(3):307-12.

40. Carvajal-Rondanelli P, Aróstica M, Marshall SH, Albericio F, Álvarez CA, Ojeda C, Aguilar L, Guzmán F. Inhibitory effect of short cationic homopeptides against gram-negative bacteria. Amino Acids. 2016;48(6):1445-56.

41. Ferreira AM, Gentile P, Sartori S, Pagliano C, Cabrele C, Chiono V, Ciardelli G. Biomimetic soluble collagen purified from bones. Biotechnol J. 2012;7(11): 1386-94.

42. Vitagliano L, Berisio R, Mazzarella L, Zagari A. Structural bases of collagen stabilization induced by proline hydroxylation. Biopolymers. 2001;58:459-64.

43. Gelse K, Poschl E, Aignera T. Collagens-structure, function, and biosynthesis. Adv Drug Deliv Rev. 2003;55:1531-46. 
44. Miles $C$, Burjanadze T, Bailey A. The kinetics of the thermal denaturation of collagen. J Mol Biol. 1995;245:437-46.

45. Ozcelikkale A, Han B. Thermal destabilization of collagen matrix hierarchical structure by freeze/thaw. PLoS One. 2016;XI(1):1-18.

46. Gautieri A, Vesentini S, Redaelli A, Alberto M. Viscoelastic properties of model segments of collagen molecules. Viscoelastic Properties Model Segments Collagen Mol. 2012;31:141-9.

47. Kwansa AL, De Vita R, Freeman JW. Tensile mechanical properties of collagen type I and its. Biophys Chem. 2016;214-215:1-10.

48. Bellinia D, Cencetti C, Sacchetta AC, Battista AM, Martinelli A, Mazzucco L, Scotto D'Abusco A, Matricardi P. PLA-grafting of collagen chains leading. J Mech Behav Biomed Mater. 2016;64:151-60.

49. Na G, Butz L, Carroll R. Mechanism of in vitro collagen fibril assembly. J Biol Chem. 1986;261(26):12290-9.

50. Baranauskienè L, Petrikaite V, Matulienè J, Matulis D. Titration Calorimetry standards and the precision of isothermal titration Calorimetry data. Int J Mol Sci. 2009;10:2752-62.

51. Kabiri M, Bushnak I, McDermot M, Unsworth L. Toward a mechanistic understanding of ionic self-complementary peptide self-assembly: role of water molecules and ions. Biomacromolecules. 2013;14:3943-50.

52. Aimé $C$, Mosser $G$, Pembouong G, Bouteiller L, Coradin T. Controlling the nano-bio interface to build collagen-silica self-assembled. Nanoscale. 2012; 4:7127-34

53. Na G, Phillips L, Freire E. In Vitro Collagen Fibril Assembly: Thermodynamic Studies. Biochemistry. 1989;28:7153-61.

54. Jelercic U. Protein self-assembly, Ljubljana; 2009 .

55. Garti N, Amar-Yuli I. Nanotechnologies for Solubilization and delivery in foods, Cosmetics and Pharmaceuticals. Pennsylvania: DEStech Publications, Inc:; 2012.

56. Djabourov M, Maquet J, Theveneau H, Leblond J, Papon P. Kinetics of gelation of aqueous gelatin solutions. British Polymer J. 1985;17(2):169-74.

\section{Publisher's Note}

Springer Nature remains neutral with regard to jurisdictional claims in published maps and institutional affiliations.

Ready to submit your research? Choose BMC and benefit from:

- fast, convenient online submission

- thorough peer review by experienced researchers in your field

- rapid publication on acceptance

- support for research data, including large and complex data types

- gold Open Access which fosters wider collaboration and increased citations

- maximum visibility for your research: over $100 \mathrm{M}$ website views per year

At $\mathrm{BMC}$, research is always in progress.

Learn more biomedcentral.com/submissions 